\title{
Effect of air pollution on onset of acute coronary syndrome in susceptible subgroups
}

\author{
M. Qorbani, ${ }^{1,3}$ M. Yunesian, ${ }^{2}$ A. Fotouhi, ${ }^{3}$ H. Zeraati ${ }^{3}$ and S. Sadeghian ${ }^{4}$
}

$$
\begin{aligned}
& \text { تأثير تلوث الهو اء على المتلازمة التاجية الحادة في المجموعات الفرعية الحسَّاسة للمخاطر }
\end{aligned}
$$

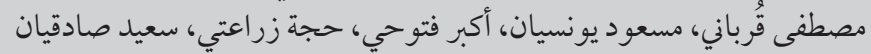

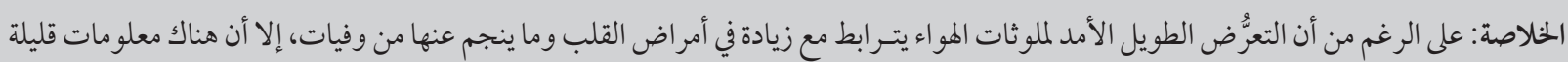

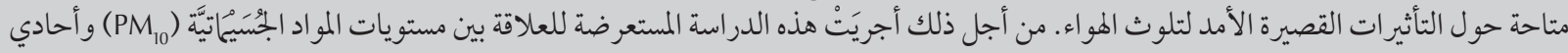

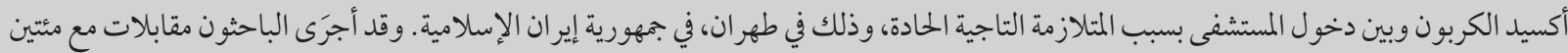

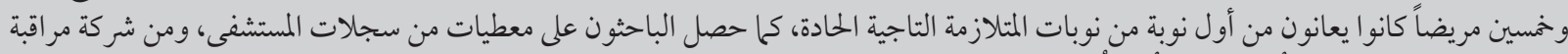

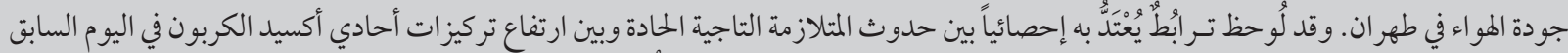

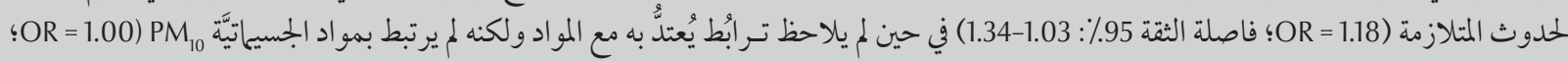

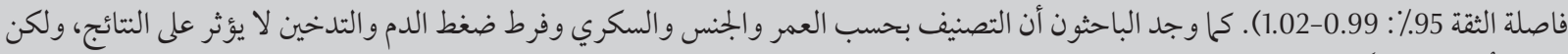

النساء كُنَّ أكثر تأثراً من الرجة جال بمستويات أحادي أكسيد الكربون (نسبة الأرجحية للنساء/ الرجال

ABSTRACT While long-term exposure to air pollutants is associated with an increase in heart diseases and mortality, little information is available about the short-term effects of air pollution. This case-crossover study assessed the relationship of particulate matter $\left(\mathrm{PM}_{10}\right)$ and carbon monoxide $(\mathrm{CO})$ levels with hospital admission for acute coronary syndrome in Tehran, Islamic Republic of Iran. We interviewed 250 patients with a first episode of acute coronary syndrome and obtained data from hospital records and Tehran Air Quality Control Company. The risk of acute coronary syndrome was significantly associated with elevated concentrations of CO the day before the event (OR 1.18; 95\% Cl: 1.03-1.34) but not significantly with $\mathrm{PM}_{10}$ (OR 1.00; 95\% Cl: 0.99-1.02). Stratification by age, sex, diabetes, hypertension and smoking status did not affect the results, but women were more susceptible than men to CO levels (OR for women/men 1.68; 95\% Cl: 1.25-2.26).

Effet de la pollution atmosphérique sur la survenue d'un syndrome coronarien aigu dans des sous-groupes vulnérables

RÉSUMÉ Alors qu'une exposition à long terme aux polluants atmosphériques est associée à une augmentation des pathologies cardiaques et de la mortalité, peu de données sont disponibles sur les effets à court terme de la pollution atmosphérique. La présente étude de cas croisés a recherché la relation entre les taux de particules, de monoxyde de carbone et le nombre des admissions à l'hôpital pour un syndrome coronarien aigu à Téhéran (République islamique d'Iran). Nous avons interrogé 250 patients présentant un premier épisode de syndrome coronarien aigu et avons obtenu des données à partir des dossiers hospitaliers et de la société de contrôle de la qualité de l'air à Téhéran (Tehran Air Quality Control Company). Le risque d'un syndrome coronarien aigu était fortement associé à des concentrations élevées de monoxyde de carbone le jour précédent I'événement (O.R. 1,18; IC à $95 \%$ : 1,03-1,34) mais faiblement associé aux taux de particules (O.R. 1,00; IC à 95 \% : 0,99-1,02). La stratification par âge, par sexe, par l'état diabétique ou hypertendu et par le statut tabagique n'influait pas sur les résultats. En revanche, les femmes étaient plus vulnérables que les hommes aux niveaux de monoxyde de carbone (O.R. pour les femmes/hommes 1,68; $95 \%$ IC à $95 \%$ : 1,25-2,26).

${ }^{7}$ School of Medicine, Golestan University of Medical Sciences, Gorgan, Islamic Republic of Iran.

${ }^{2}$ Department of Environmental Heath, School of Public Heath, Tehran University of Medical Sciences, Tehran, Islamic Republic of Iran (Correspondence to M. Yunesian:yunesian@tums.ac.ir).

${ }^{3}$ Department of Epidemiology and Biostatistics, School of Public Health, Tehran University of Medical Sciences, Tehran, Islamic Republic of Iran. ${ }^{4}$ Tehran Heart Centre, Tehran University of Medical Sciences, Tehran, Islamic Republic of Iran.

Received: 22/06/10; accepted: 31/08/10 


\section{Introduction}

Epidemiological studies worldwide have shown that exposure to high concentrations of air pollutants are associated with an increase in heart diseases and mortality [1-4]. Nevertheless, little information about the short-term effects of air pollution is available using a methodology that minimizes the personal characteristics of patients as confounders (case-crossover design). The harmful effects of particulate matter up to $10 \mu \mathrm{m}$ in size $\left(\mathrm{PM}_{10}\right)$ and carbon monoxide $(\mathrm{CO})$ concentrations have been shown in multiple studies of hospital admissions for respiratory and heart diseases $[1-5]$. These results suggest that air pollution is a risk factor for respiratory disease and acute cardiovascular events. More recently studies have shown susceptibility of some subgroups to the effect of air pollution [6-8]. For example, Zanobetti et al. reported that patients with diabetes might be more susceptible to heart diseases associated with particulate matter [9].

Acute coronary syndrome (ACS) includes unstable angina and myocardial infarction (MI). In both conditions the coronary artery blood flow is impaired due to arteriosclerosis or thrombosis. In the Islamic Republic of Iran Hosseinpoor et al. showed that hospital admissions for angina pectoris in Tehran increased with increasing CO but did not relate to $\mathrm{PM}_{10}$ levels (using a time-series approach [10]). In the present study in Tehran we investigated the effect of air pollution ( $\mathrm{CO}$ and $\mathrm{PM}_{10}$ levels) in the 24 hours before the onset of ACS and whether the classic risk factors of ACS (age, sex, diabetes, hypertension and smoking status) acted as potential effect modifiers.

\section{Methods}

We used a case-crossover design to evaluate the association between 24hour average concentrations of $\mathrm{CO}$ and
$\mathrm{PM}_{10}$ and risk of hospital admission for ACS. The study was conducted from 4 April to 10 September 2007.

\section{Sample}

All 250 patients with their first episode of ACS who were emergency admissions to Tehran heart centre were interviewed. Interviews were conducted by trained research nurses on the emergency ward as soon as possible after the admission. For inclusion in the study, patients were required to have following criteria: typical symptoms of ACS onset (while in Tehran city); positive ECG (ST segment elevation or $\mathrm{T}$ inversion); creatine kinase level $\geq 1$ above the upper limit of normal for the hospital laboratory performing the test; and the ability to complete a structured interview.

\section{Data collection}

We considered the classic risk factors of ACS (age, sex, diabetes, hypertension and smoking status) as potential effect modifiers. The information on hypertension, diabetes and smoking status was taken from the hospital database.

Hourly and daily air pollution measurements were taken from the Tehran Air Quality Control Company. This company has 7 fixed and 2 portable monitoring stations within the city. We computed local daily mean values of $\mathrm{PM}_{10}$ and $\mathrm{CO}$ using an algorithm that accounted for the different monitor-specific means and variances [11]. $\mathrm{PM}_{10}$ concentration was measured continuously with beta-ray atomic absorption and $\mathrm{CO}$ concentration was measured with a continuous non-dispersive infrared analyser. The $\mathrm{PM}_{10}$ series had some occasional missing observations, and we replaced the missing values with the predicted values from a regression where we controlled for season and weather variables and which have been shown to be a good predictor of fine particle concentration.

\section{Statistical analysis}

The analysis of case-crossover data is similar to stratified data analysis [12-14]. For each subject, data on pollutants in a case period 24 hours before the onset of ACS was matched to data for a control period exactly a week before. This allowed us to control for confounders due to the day of onset of ACS. Conditional logistic regression analysis was fitted to the data to calculate the odds ratio (OR) and 95\% confidence interval (CI) [15]. Exposures to $\mathrm{PM}_{10}$ and $\mathrm{CO}$ were entered as continuous variables in the model. Relative humidity and temperature were included continuously as confounding variables in a conditional logistic model. Holiday status of that day of the week was analysed in 3 categories (holiday, day after holiday and other). Due to the lack of normal distribution of the data Wilcoxon test for paired samples was used to compare independent variables in the case and control periods.

Stratified analysis was used to assess the effect modification of the association between onset of ACS and $\mathrm{CO}$ and $\mathrm{PM}_{10}$ exposure. We considered age (s 60 and $>60$ years), sex, smoking status, diabetes and hypertension as probable effect modifiers. Smoking status was analysed in 3 categories: never smoker, current smoker and ex-smoker. Hypertension was defined as systolic blood pressure $\geq 140 \mathrm{mmHg}$ or diastolic blood pressure $\geq 90 \mathrm{mmHg}$ (in physician's notes) or use of antihypertensive drugs. Diabetes was determined based on fasting blood sugar level $>126 \mathrm{mg} /$ $\mathrm{dL}$ or use of antidiabetic medication. These results were presented as OR and $95 \%$ CI. $P$-values $<0.05$ were considered statistically significant. Analyses were conducted using Stata/SE, version 10.0 software.

\section{Results}

Among 250 participants, $20 \%$ were current smokers, $41 \%$ were ex-smokers and 
the rest were never smokers (Table 1). One-quarter (24\%) were hypertensive and $34 \%$ had diabetes. The sex distribution of participants was approximately equal ( $51 \%$ male versus $49 \%$ female). The mean age of the study group was 63 (SD 14) years and $58 \%$ of subjects were $\leq 60$ years old.

Table 2 show the distribution of $24-$ hour average concentration of pollutants $\left(\mathrm{CO}\right.$ and $\left.\mathrm{PM}_{10}\right)$, relative humidity and temperature in the case and control periods. A statistically significant difference between the case and control periods was seen only in mean daily concentration of $\mathrm{CO}$.

Table 3 summarizes the association between air pollutants $\left(\mathrm{CO}\right.$ and $\mathrm{PM}_{10}$ as continuous measures) and the risk of onset of ACS. A statistically significant relationship was seen only for elevated risks of ACS and mean daily concentration of CO. The OR was 1.18 (95\% CI: 1.03-1.35) unadjusted and 1.18 (1.03-1.35) when adjusted for temperature, humidity and holiday status. The 24-hour average concentration of
$\mathrm{PM}_{10}$ also showed a positive association but did not reach statistical significance.

The relationship between $\mathrm{CO}$ level and ACS was not significantly affected by age, smoking status, diabetes or hypertension $(P>0.05)$ (Table 1). However, there was as association of CO level and ACS with patient's sex. Stratified analyses by age, sex, diabetes, hypertension and smoking status are displayed in Table 4. The risk for women was significantly greater than for men with regard to CO level (OR 1.68; 95\% CI: 1.25-2.26) (interaction P-value < $0.001)$. Stratification by these potential effect modifiers did not change the relationship between $\mathrm{PM}_{10}$ and ACS.

\section{Discussion}

Although prior evidence have shown that elevated levels of particulate matter are linked with MI and cardiovascular diseases [16,17], this study could not demonstrate any association between an increase in 24-hour average concentration of $\mathrm{PM}_{10}$ and ACS on the day before onset of the event. Even stratification of cases by effect modifiers did not change this association.

In this study a high 24-hour average concentration of $\mathrm{CO}$ on the day before onset was associated with ACS. This result was consistent with Hosseinpoor et al.'s results in Tehran which showed a positive association between $\mathrm{CO}$ and angina pectoris in a retrospective time-series study [10]. Adjustment for weather conditions and holiday status did not change this association dramatically. Women had a higher OR for the association between CO level and ACS compared with men.

As Tehran is a big city with more than 10 million inhabitants, a large number of people may be exposed to air pollution and may be affected as a consequence of high levels of air pollutants. Although the concentration of pollutants such as $\mathrm{CO}$ in ambient air may not be especially high most of the time, we can expect a considerable rise in admissions due to the huge number of people exposed, keeping in mind

\begin{tabular}{|c|c|c|c|c|c|c|}
\hline \multirow[t]{2}{*}{ Variable } & \multirow{2}{*}{$\begin{array}{c}\text { No. of } \\
\text { patients }\end{array}$} & \multirow[t]{2}{*}{$\%$} & \multicolumn{2}{|c|}{ Mean (SD) CO level (ppm) } & \multicolumn{2}{|c|}{ Mean (SD) PM 10 level $\left(\mu \mathrm{g} / \mathrm{m}^{3}\right)$} \\
\hline & & & Case period & Control period & Case period & Control period \\
\hline \multicolumn{7}{|l|}{ Sex } \\
\hline Male & 129 & 51 & $3.71(2.43)$ & $3.18(2.32)$ & $46.5(26.3)$ & $39.6(22.7)$ \\
\hline Female & 121 & 49 & $3.89(2.38)$ & $3.09(2.30)$ & $46.7(25.6)$ & $39.5(23.2)$ \\
\hline \multicolumn{7}{|l|}{ Age (years) } \\
\hline$\leq 60$ & 143 & 58 & $3.79(2.44)$ & $3.15(2.31)$ & $46.4(25.8)$ & $39.6(22.7)$ \\
\hline$>60$ & 107 & 42 & $3.80(2.41)$ & $3.12(2.39)$ & $46.9(25.8)$ & $39.7(22.9)$ \\
\hline \multicolumn{7}{|l|}{ Smoking status } \\
\hline Smoker & 49 & 20 & $3.88(2.41)$ & $3.11(2.31)$ & $46.6(27.0)$ & $39.8(22.8)$ \\
\hline Ex-smoker & 103 & 41 & $3.77(2.37)$ & $3.17(2.34)$ & $46.7(26.1)$ & $39.6(23.0)$ \\
\hline Never smoker & 98 & 39 & $3.78(2.39)$ & $3.15(2.32)$ & $46.4(27.9)$ & $39.6(23.1)$ \\
\hline \multicolumn{7}{|l|}{ Diabetes } \\
\hline Yes & 85 & 34 & $3.85(2.41)$ & $3.09(2.37)$ & $46.4(26.2)$ & $40.5(22.0)$ \\
\hline No & 165 & 66 & $3.69(2.44)$ & $3.17(2.32)$ & 46.7 (25.9) & $39.1(22.9)$ \\
\hline \multicolumn{7}{|l|}{ Hypertension } \\
\hline Yes & 65 & 24 & $3.82(2.40)$ & $3.13(2.30)$ & $46.5(25.7)$ & $40.6(22.8)$ \\
\hline No & 185 & 76 & $3.71(2.39)$ & $3.14(2.34)$ & $46.6(25.7)$ & $39.2(22.5)$ \\
\hline
\end{tabular}

$S D=$ standard deviation . 


\begin{tabular}{|c|c|c|c|}
\hline \multicolumn{4}{|c|}{$\begin{array}{l}\text { Table } 2 \text { Distribution of mean levels of particulate matter }\left(\mathrm{PM}_{10}\right) \text { and carbon } \\
\text { monoxide }(\mathrm{CO}) \text { and weather conditions in the case period }(24 \text {-hours before } \\
\text { event) and control period ( } 1 \text { week before) for patients with first episode of acute } \\
\text { coronary syndrome }(n=250)\end{array}$} \\
\hline Variable & $\begin{array}{l}\text { Case period } \\
\text { Mean (SD) }\end{array}$ & $\begin{array}{c}\text { Control period } \\
\text { Mean (SD) }\end{array}$ & $P$-value ${ }^{a}$ \\
\hline CO level (ppm) & $3.79(2.37)$ & $3.14(2.29)$ & 0.01 \\
\hline $\mathrm{PM}_{10}$ level $\mu \mathrm{g} / \mathrm{m}^{3}$ ) & $46.6(25.5)$ & $39.6(22.0)$ & 0.18 \\
\hline Temperature $\left({ }^{\circ} \mathrm{C}\right)$ & $20.2(4.5)$ & $19.8(4.5)$ & 0.48 \\
\hline Humidity (\%) & $35.3(18.5)$ & $34.1(14.4)$ & 0.57 \\
\hline
\end{tabular}

${ }^{a}$ Wilcoxon test

$S D=$ standard deviation

that the odds ratio was not so small. So these effects may be of significant public health importance because exposure to $\mathrm{CO}$ is ubiquitous and involuntary in big cities such as Tehran.

Our results are consistent with Sullivan et al.'s results [6]. They did not demonstrate any association between levels of particulate matter and MI. Stratification of cases by age, diabetes and hypertension did not modify this association, which agrees with our results. However, our results concerning the association between $\mathrm{PM}_{10}$ and ACS contradict the results of Peters et al. in Boston and D'Ippoliti et al. in Rome, who showed positive associations between total suspended particulate levels and MI $[7,16]$. Differences in fine particulate matter composition between cities may explain this discrepancy. Particulate matter in Tehran is low in sulfates [18]. Analyses of particulate matter in Canada demonstrated that sulfate in particulate matter has a direct association with cardiovascular disease [19]. Another reason for differences between our results and Peters et al. and
D'Ippoliti's studies is that these studies assessed all particulate matters and $\mathrm{NO}_{2}$ as pollutants. As $\mathrm{NO}_{2}$ is converted to nitrates and it contributes to fine particle mass, it may explain the difference.

Sensitivity of susceptible subgroups to air pollution is has been debated and few studies have been performed to clarify this ambiguous point $[8,20,21]$. The effect modification by sex that was seen in our data (with a stronger effect among women) is not surprising given similar results already observed in other studies on air pollution and respiratory and cardiovascular disease mortality [22-24]. One explanation of women's greater response to air pollution may be their bronchial hyper-responsiveness to soot and pollutants [25]. Stratification by diabetes, hypertension, smoking status and age did not change the associations and ORs in our study.

Estimates for the association between $\mathrm{PM}_{10}$ and ACS were similar among those with or without the potential effect modifiers. Zanabetti et al. demonstrated that diabetic patients are more susceptible to cardiovascular

\begin{tabular}{|c|c|c|}
\hline \multicolumn{3}{|c|}{$\begin{array}{l}\text { Table } 3 \text { Odds ratio for } 24-h o u r \text { mean levels of particulate matter }\left(\mathrm{PM}_{10}\right) \text { and carbc } \\
\text { monoxide }(\mathrm{CO}) \text { for patients with first episode of acute coronary syndrome }(n= \\
\text { 250) }\end{array}$} \\
\hline Pollutant & $\begin{array}{l}\text { Unadjusted } \\
\text { OR }(95 \% \mathrm{Cl})\end{array}$ & $\begin{array}{c}\text { Adjusted } \\
\text { OR }(95 \% \mathrm{Cl})^{\mathrm{a}}\end{array}$ \\
\hline CO level (ppm) & $1.18(1.03-1.35)$ & 1.18 (1.03-1.35) \\
\hline $\mathrm{PM}_{10}$ level $\left.\mu\right) \mathrm{g} / \mathrm{m}^{3}$ ) & $1.00(0.99-1.02)$ & $1.00(0.99-1.02)$ \\
\hline
\end{tabular}

${ }^{a}$ Adjusted for temperature, humidity and holiday status. $O R=$ odds ratio; $C I=$ confidence interval. events (and hospital admissions) as a result of particulate matter exposure [26]. There is a need for further research on effect modifiers.

The most advantageous feature of the case-crossover design used in our study is that it minimized the probability of confounding by individual variables $[13,14]$. Confounding may occur because of time-varying risk factors $[27,28]$, such as time of day or weather conditions, which were considered in the multivariate analysis. As individuals comprise study units in this type of study, this approach can assess effect modification by within-person factors; however, the statistical power of the method is lower than in time-series analysis $[29,30]$. The main problem of this design is the selection of the control period $[31,32]$. Levy et al. presented a time-stratified method that seems to give the least biased strategy [33].

Our study used the data available from multiple air pollution monitoring stations spread throughout the city area that enabled us to determine a reasonable estimate of the level of exposure of the participants. We examined patients with their first ACS event. These strategies might have increased the possibility of finding an association. There are some limitations to our study, however, that may originate from unidirectional case-crossover studies. Such designs might be sensitive to trends in the exposure and the outcome $[27,28]$. There is the possibility of downward bias in this study due to the relatively short interval (1 week) between the hazard and control periods that may lead to low variability of exposure. Another factor is that we were not able to include the levels of fine particulates $\left(\mathrm{PM}_{2.5}\right)$ in the analysis. Including only patients able to complete structured interview may have lead to the exclusion of more serious cases of ACS. This may bias our results to null, because the more severe cases are expected to have stronger association with air pollution. The physicians and research team in 


\begin{tabular}{|c|c|c|c|c|}
\hline \multirow[t]{2}{*}{ Variable } & \multicolumn{2}{|c|}{$\mathrm{PM}_{10}$ level } & \multicolumn{2}{|c|}{ CO level } \\
\hline & OR $(95 \% \mathrm{CI})$ & $P$-value & OR $(95 \% \mathrm{CI})$ & $P$-value \\
\hline Diabetes (yes vs no) & $1.00(0.97-1.03)$ & 0.87 & $1.20(0.92-1.56)$ & 0.17 \\
\hline Hypertension (yes vs no) & $0.98(0.95-1.01)$ & 0.27 & $1.11(0.83-1.47)$ & 0.48 \\
\hline Age > 60 (yes vs no) & $0.99(0.97-1.01)$ & 0.55 & $1.13(0.86-1.48)$ & 0.36 \\
\hline Female (vs male) & $0.98(0.95-1.01)$ & 0.39 & $1.68(1.25-2.26)$ & $<0.01$ \\
\hline Never smoker (vs smoker) & $1.00(0.97-1.03)$ & 0.81 & $0.77(0.51-1.17)$ & 0.23 \\
\hline Ex-smoker (vs smoker) & $0.98(0.95-1.01)$ & 0.39 & $0.82(0.43-1.56)$ & 0.35 \\
\hline
\end{tabular}

$O R=$ odds ratio $; C l=$ confidence interval.

this study were not informed about air pollution conditions at the time of data collection and so we would not expect considerable information bias to occur. Although we measured and adjusted for probable confounders in our study, random error in measurement of these might have occurred, and this could increase the residual confounding.

In conclusion, this study provides evidence that short-term exposure to elevated concentrations of $\mathrm{CO}$ can trigger ACS and that women are more susceptible than men.

\section{Acknowledgements}

The Tehran University of Medical Sciences supported this research. We thank the Tehran Heart Centre and Tehran Air Quality Control Company for their contributions.

\section{References}

1. Bascom R, Bromberg PA. Health effect of outdoor air pollution. American Journal of Respiratory and Critical Care Medicine, 1996, 153:3-50.

2. Dockery DW, Pope CA. An association between air pollution and mortality in six US cities. New England Journal of Medicine, 1993, 329:1753-1759.

3. Hoek G, Brunekreef B, Fischer P. The association between air pollution and heart failure, arrhythmia, embolism, thrombosis, and other cardiovascular cause of death in a time series study. Epidemiology, 2001, 12:355-357.

4. Peters A, Frohlich M, Doring A. Particulate air pollution is associated with an acute phase response in men. European Heart Journal, 2007, 324:143-146.

5. Schwartz J. Particulate air pollution and daily mortality: a synthesis. Public Health Review, 1991, 19:39-60.

6. Sullivan J et al. Relation between short-term fine-particulate matter exposure and onset of myocardial infarction. Epidemiology, 2005, 16:41-48.

7. Peters A et al. Increased particulate air pollution and the triggering of myocardial infarction. Circulation, 2001, 103:28102815.

8. Goldberg MS, Bailar JC, Burrnett RT. Identifying subgroups of the general population that may be susceptible to short-term increases in particulate air pollution: a time-series study in Montreal, Quebec. Research Report (Health Effects Institute), 2000, 97:107-113.

9. Zanobetti A, Schwartz J, Gold D. Are there sensitive subgroups for the effects of airborne particle? Environmental Health Perspectives, 2000, 108:841-845.

10. Hosseinpoor AR et al. Air pollution and hospitalization due to angina pectoris in Tehra, Iran: a time-series study. Environmental Research, 2005, 99:126-131.

11. Zanobetti A, Schwartz J, Dockery DW. Airborne particles are a risk factor for hospital admissions for heart and lung disease. Environmental Health Perspectives, 2000, 108:1071-1077.
12. Mittleman MA, Maclure M, Tofler GH. Control sampling strategies for case-crossover studies: an assessment of relative efficiency. American Journal of Epidemiology, 1995, 142:92-98

13. Maclure M. The case-crossover design: A method for studying transient effects on the risk of acute events. American Journal of Epidemiology, 1991, 133:144-153.

14. Maclure M, Mittleman MA. Should we use a case-crossover design? Annual Review of Public Health, 2000, 21:193-221.

15. Jaakkola JJK. Case-crossover design in air pollution epidemiology. European Respiratory Journal, 2003, 21:81-85.

16. D'Ippoliti D et al. Air pollution and myocardial infarction in Rome: A case-crossover analysis. Epidemiology (Cambridge, Mass.), 2003, 14:528-535.

17. Dockery DW, Stone PH. Cardiovascular risks from fine particulate air pollution. New England Journal of Medicine, 2007, 356:511-513.

18. Masjedi M, Khalilzade S, Sayeedfar K. [Association between air pollution and cardiac respiratory diseases in Tehran]. Tehran Ministry of Health and Population, 2002 [n Farsi].

19. Goldberg MS, Burrnett RT, Bailar JC. The association between daily mortality and ambient air particle pollution in Montreal, Quebec: 2 cause specific mortality. Environmental Research, 2001, 86:26-36.

20. Nnesi-Maesano I et al. Subpopulations at increased risk of adverse health outcomes from air pollution. European Respiratory Journal, 2003, 21:57-63.

21. Bateson TF, Schwartz J. Who is sensitive to the effects of particulate air pollution on mortality? A case-crossover analysis of effect modifiers. Epidemiology (Cambridge, Mass.), 2004, 15:143-149.

22. Jarvis $\mathrm{D}$ et al. The association of respiratory symptoms and lung function with the use of gas for cooking: European Community Respiratory Health Survey. European Respiratory Journal, 1998, 11:651-658. 
23. Dow L, Fowler L, Pheleps L. Prevalence of untreated asthma in a population sample of 6000 older adults in Bristol, UK. Thorax, 2001, 56:472-476.

24. Schwela D. Air pollution and health in urban areas. Reviews on Environmental Health, 2000, 15:13-42.

25. Leynaert B et al. Bronchial hyper responsiveness more frequent in women than in men? American Journal of Respiratory and Critical Care Medicine, 1997, 156:1413-1420.

26. Zanobetti A, Schwartz J. Are diabetic more susceptible to the health effects of airborne particles. American Journal of Respiratory and Critical Care Medicine, 2001, 164:831-833.

27. Forastiere $\mathrm{F}$ et al. A case-crossover analysis of out-of hospital coronary deaths and air pollution in Rome, Italy. American Journal of Respiratory and Critical Care Medicine, 2005, 172:1549-1555.

28. Bateson TF, Schwartz J. Control for seasonal variation and time trend in case-crossover studies of acute effects of envi- ronmental exposures. Epidemiology (Cambridge, Mass.), 1999, 10:539-544.

29. Navidi W. Bidirectional case-crossover designs for exposures with time trends. Biometrics, 1998, 54:596-605.

30. Karen YF et al. Comparison of time series and case-crossover analyses of air pollution and hospital admission data. International Journal of Epidemiology, 2003, 32:1064-1070.

31. Navidi W, Weinhand E. Risk set sampling for case-crossover designs. Epidemiology (Cambridge, Mass.), 2002, 13:100-105.

32. Holly J, Lianne S, Tomas L. Overlap bias in the case-crossover design, with application to air pollution exposures. British Medical Journal, 2004, 213:1654-1666.

33. Levy $\mathrm{D}$ et al. A case-crossover analysis of particulate matter air pollution and out-of-patient primary cardiac arrest. Epidemiology, 2001, 12:193-199.

\section{Transport (road transport): shared interests in sustainable outcomes (Social Determinants of Health Sectoral Briefing Series, 3)}

By providing information on other sectors agendas and policy approaches, and their health impacts, and by illustrating areas for potential collaboration, the Social Determinants of Health Sectoral Briefing Series aims to encourage more systematic dialogue and problem solving, and more collaboration with other areas of government. The target audience for the series is public health officers, who are not experts on determinants of health, but who have responsibilities for dealing with a broad range of development issues and partners.

The above-mentioned briefing describes challenges facing transport policy-makers and authorities, how they address them, and areas for potential collaboration between health and transport. There are three sections. First, an overview of the transport sector, which covers mutual public policy interests of transport and health; global trends in road transport; and transport policy challenges from the perspective of the transport sector. Second, a more detailed description is given of 5 policy goals related to the transport sector and policy approaches, health impacts and pathways, and examples of areas for joint work between health and transport are covered. Finally, the briefing provides summary messages to permit those with limited time to obtain a well-rounded perspective of the topic by reading only sections one and three.

Further information about this and other WHO publications is available at: http:/ /apps.who.int/ bookorders/anglais/homel.jsp 